\title{
ENTRE EL CANON DE LA LITERATURA OCCIDENTAL Y LAS TRADICIONES NARRATIVAS SUBALTERNAS: TENSIONES Y SOLU- CIONES EN LA RECEPCIÓN DE LA NOVELA DEL CARIBE COLOMBIANO
}

\author{
Juan Moreno Blanco ${ }^{1}$
}

Resumen: A propósito de cuatro novelas de tres escritores del Caribe colombiano, Manuel Zapata Olivella, Gabriel García Márquez y Germán Espinosa, el presente artículo busca poner a prueba una teoría sobre la relación entre literatura y oralidad. Se pretende mostrar que esta teoría, como toda teoría, puede, no obstante sus ventajas, contribuir a perpetuar fronteras y jerarquías canónicas que históricamente han vivido en armonía con las ideologías hegemónicas de la ciudad letrada.

Palabras Clave: Ficcionalización de la oralidad, Subalternidad, Canonicidad, Gabriel García Márquez, Manuel Zapata Olivella, Germán Espinosa.

Resumo: A propósito de quatro romances de três escritores do Caribe colombiano - Manuel Zapata Olivella, Gabriel García Márquez y Germán Espinosa -, o presente artigo busca colocar em xeque uma teoria sobre a relação entre literatura e oralidade. Pretende-se mostrar que esta teoria, como toda teoria, pode, não obstante suas vantagens, contribuir para perpetuar fronteiras e hieraquias canônicas que historicamente têm vivido em harmonia com as ideologias hegemônicas da ciudade letrada.

Palavras-chave: Ficcionalização da oralidade, Subalternidade, Canonicidade, Gabriel García Márquez, Manuel Zapata Olivella, Germán Espinosa.

Todo universo cultural y literario, nacional o transnacional, se halla sometido a perspectivas o rejillas de interpretación a partir de las cuales los textos son escogidos y destinados a la lectura de una comunidad. Así, la totalidad de obras son diferenciadas e, inevitablemante, jerarquizadas. Es a ese propósito que un crítico norteamericano, J. Guillory, establece un contraste entre la biblioteca y el canon, cada cual teniendo de suyo sus leyes de funcionamiento y existencia. Mientras la biblioteca contiene "todos" los libros, el canon conlleva actos de elección frutos del ejercicio de juicios de valor que un bibliotecario puede, las más de las veces, ignorar. La biblioteca sería entonces como un territorio sobre el cual el canon traza un mapa o una guía para un viaje (POZUELO YVANCOS, 2000, p. 48). Siguiedo

1 Profesor de la Escuela de Estudios Literarios de la Universidad del Valle, Cali, Colombia. Docteur en Études Ibériques et Ibéro-Américaines de la Université Michel de MomtaigneBordeaux 3, Francia. Autor de "Las Crónicas de Indias y la expresión americana", Premios de Ensayo Jorge Isaacs, 1998 y de La cepa de las palabras. Ensayo sobre la relación del universo imaginario wayún y la obra literaria de Gabriel García Márquez, Kassel, Edition Reichenberger, 2002. Enreço eletrônico: jmorenofr@yahoo.fr. 
esta puesta en contraste, nosotros, docentes, investigadores y críticos literarios, orientadores de las interpretaciones, seríamos los cartógrafos. Nuestras lecturas, nuestros comentarios, nuestras listas y nuestros programas de enseñanza trazarían las líneas imaginarias sobre el territorio de la biblioteca, dándole una organización diferente a la de su distribución física en los anaqueles. Ahora bien, imaginando que ese mapa existe por el hecho mismo de la existencia de instituciones que guían la interpretación (KERMODE, 1998), no podemos dejar de constatar que las líneas que lo dibujan son susceptibles de mobilidad y son de naturaleza compleja pues viven presas de las tensiones que existen entre teoría e ideología.

A propósito de las líneas del mapa del territorio de "la" biblioteca literaria latinoamericana de la segunda mitad del siglo XX, como a propósito de cualquier literatura del mundo de hoy, hay que reconocer que éstas, además de su desempeño en el trazado de caminos hechos para orientarse, realizan también la función de delimitación entre un interior y un exterior ya que, al referirse a un criterio de interpretación, los cartógrafos insertarán cada obra literaria en una parcela específica del mapa. Quisiéramos intentar el abordaje de algunas novelas de la costa caribe colombiana dejándonos guiar por criterios que se quisieran estrictamente teóricos para, luego, mostrar que en el seno de una rejilla de interpretación se han infiltrado criterios que en fin de cuentas tienen vínculos con representaciones e inclinaciones ideológicas de una gran longevidad.

En los estudios literarios sobre el sub-continente latinoamericano, es corrientemente aceptado el tomar como uno de los rasgos distintivos de la novela latinoamericana el hecho de que ésta expresa la naturaleza culturalmente heterogénea de sociedades que tuvieron recorridos históricos bastantes semejantes. Los indispensables estudios de Antonio Cornejo Polar y Angel Rama hacen las veces de paradigmas sobre los cuales se ha erigido una tradición interpretativa de lo que algunos llaman la Modernidad Heterogénea. Y es en ese marco que las investigaciones sobre literatura han debido abrirse al estudio de la oralidad pues esta dimensión cultural latinoamericana debía ser conocida para comprender la manera como las tradiciones narrativas no escritas de los sujetos sociales subalternos han venido a enriquecer las corrientes de la cultura letrada. A este propósito debemos evocar los trabajos de Martin Lienhard, sobre todo su libro pionero La voz y su buella (1990). Pero, en lo que concierne específicamente a la relación de la novela y la oralidad tocó esperar el trabajo de Carlos Pacheco La comarca oral. La ficcionalización de la oralidad cultural en la narrativa latinoamericana contemporánea (1992). En este trabajo, a través del estudio de novelas del mejicano Juan Rulfo, del brasileño João Guimarães Rosa y del paraguayo Augusto Roa Bastos, Pacheco establece, quizá sin ser consciente de ello, un criterio canónico que delimita la parcela de un grupo de narradores literarios en donde podríamos poner otros nombres parejamente representativos tales como los de José María Arguedas, Miguel Angel Asturias, Rosario 8 A Cor das Letras - UEFS, n. 8, 2007 
Castellanos, etc. La presencia de la oralidad, de la ficcionalización de la oralidad, en la escritura de estos autores sería entonces un criterio teórico que bien podría funcionar como línea imaginaria que nos guía en el territorio-biblioteca de la literatura latinoamericana. En este grupo de representantes de, según la expresión de Antonio Cornejo Polar, "la totalidad contradictoria", o, según la de Angel Rama, "la transculturación narrativa", no podemos dejar de constatar la ausencia del más célebre escritor del caribe colombiano, Gabriel García Márquez. Sobre esto volveremos más adelante.

Es siguiendo esta línea imaginaria trazada por la teoría que intentaremos leer algunas de las novelas de tres escritores del caribe colombiano. Con esto queremos hacer un test a un criterio teórico en su radio de influencia sobre el "territorio" literario para verificar su pertinencia o, al contrario, sus fallas y sus limitaciones. Nos parece que los escritores de esta región del país colombiano, crisol de una vasta heterogeneidad cultural excéntrica a Bogotá, antigua capital de un virreinato del imperio español y capital del proyecto letrado-republicano (RAMA, 1984), son en toda Colombia aquellos que probablemente más han integrado la oralidad a sus proyectos narrativos.

\section{CHANGÓ EL GRAN PUTAS (1983)}

La novela del escritor Manuel Zapata Olivella (1920) es una ilustración perfecta del modelo de ficcionalización de la oralidad de Carlos Pacheco. Encontramos los cuatro aspectos de incorporación de la oralidad cultural a la narración literaria: el nivel temático, el plano lingüístico, la proliferación narrativa y, finalmente, el pensamiento y la gnoseología mítica. Changó el gran putas funciona como una contra-historia de la historia centralizada de la sociedad criolla que ha querido ser presentada como la "historia nacional". Una multiplicidad de voces que pertenecen a personajes diversos cuenta las vicisitudes de aquellos, descendientes de Changó, divinidad expulsada del pantéon africano, que en Colombia o en otros países del continente americano luchan por la libertad del negro. Los sujetos sociales son los esclavos que cuentan y viven la historia en la que se encuentra su identidad y sus referencias en tanto que civilización venida de Africa.

En la historia cultural de Colombia, esta novela introduce por primera vez la realidad del "Palenque" (espacio de vida de los cimarrones) como lugar de producción de una discursividad y de una memoria opuesta a la de la ciudad letrada. Por ello, esta invención novelesca viene a complicar las coordenadas de la historia de la literatura colombiana, haciendo que se amplien las márgenes de la memoria cultural e histórica hasta el espacio/tiempo de la puesta en esclavismo en Africa y la travesía del Atlántico en los barcos negreros. Este espacio/tiempo otro, es también una puesta a distancia de las concepciones heredadas de Occidente en cuanto a la persona humana, pues el espacio/tiempo de los afro-colombianos y afro-americanos 
incluye dimensiones antropológicas tales como la circularidad entre el pasado, el presente y el futuro, y la coexistencia entre muertos y vivos (Captain-Hidalgo, 1984). En la parcela de novelas de la ficcionalización de la oralidad, Changó el gran putas demuestra perfectamente la pertinencia de esta línea teórica sobre el territorio de la novela del caribe colombiano.

\section{CIENAÑOS DE SOLEDAD (1967)}

En la historia de la literatura colombiana Cien años de soledad ha sido uno de los objetos más trazados por los cartógrafos de la interpretación. Muchos de ellos están de acuerdo en señalar que esta novela funciona como una metáfora de la historia de la sociedad colombiana y hay quienes afirman que lo es también de latinoamerica toda. No obstante, la crítica reconoce que hay un elemento que hace falta cuando se quiere mirar esta novela como una empresa narrativa "totalizante": el componente cultural amerindio. Para ilustrar este punto, citaremos el comentario de Lucila Inés Mena sobre el silencio de los amerindios en Cien años de soledad:

Si queremos seguir la cronología, debemos comenzar con el mundo pre-
hispánico, para lo cual es inevitable que nos refiramos a la enfermedad del olvido
y a la conexión que se establece entre ésta y los indígenas, pues en el olvido po-
demos ver una referencia a la conquista y al destino de las razas aborígenes [...]
su aspecto más serio no es la falta de sueño sino el olvido progresivo que va bo-
rrando de su mente "la identidad de las personas y aun de la conciencia del pro-
pio ser hasta hundirse en una especie de idiotez sin pasado". Al parecer existe
aquí una clara referencia a la conquista, la que al someter por la violencia y la
fuerza a las razas indígenas, las privó de su lengua, su cultura, su identidad y las
relegó a un estado permanente de represión y servidumbre. No es casual que Vi-
sitación y Cataure, a pesar de su origen noble, sean los sirvientes de la casa de los
Buendía, como tampoco es casual que ellos sean los causantes de la enfermedad
del insomnio (1979, p. 201-202).

Dado que todo dejaba pensar que existía una frontera impermeable entre esta novela y las tradiciones narrativas amerindias, la crítica buscó más bien la influencia de la oralidad cultural en Cien años de soledad desde la música costeña de acordeón, más conocida como vallenato; si tenemos en cuenta los criterios de la teoría de Carlos Pacheco, la presencia de la oralidad se reduce a la tematización del personaje-músico Francisco el Hombre, y en esta novela no habría otra ficcionalización de la oralidad. Con todo, había elementos temáticos del mundo narrado no resueltos por las diversas interpretaciones, tales como la presencia de lo sobrenatural y de comportamientos y acciones humanas que salen de la lógica del modelo Occidental de civilización, y es justamente a ese título que el personaje Melquíades puede ser visto como una suerte de modelo existancial paradigmático - no solamente de esta novela sino de casi toda la obra narrativa de Gabriel García Már- 
quez. Ahora bien, en las tres décadas de críticas que siguieron a la aparición de Cien años de soledad no conocemos sino una, emprendida por Stephan Minta, que sugería la relación de este "modelo existencia" singular con el mundo amerindio:

\begin{abstract}
Melquiades, too, is a kind of eternal priest-king. He has many of the attributes of a shaman, the traditional priest-doctor among the American Indians: shamans are pre-eminent in their knowledge of myths and of the meaning of myths; they are able to maintain close contact with the world of spirits, to travel to the spirit world, and to return with their knowledge enhanced; they have the power of bilocation, enabling them to be seen simultaneously in different places; they have skill in divination, in poetry, and in magical medicine, and, in general, they serve as the repository of a wisdom beyond ordinary people's power to attain (1987, p. 151).
\end{abstract}

Esta hipótesis tenía el mérito de aproximar la literatura del escritor a las características culturales del Mundo Americano, sin embargo ella no dió lugar a una argumentación más profunda que permitiera leer la célebre novela a la luz del mundo imaginario amerindio y de sus tradiciones narrativas. No obstante, gracias a las recientes declaraciones del novelista mismo, hoy sabemos que en su niñez él creció (como José María Arguedas, Augusto Roa Bastos y muchos otros novelistas latinoamericanos) en contacto cultural con una civilización amerindia. En efecto, el escritor aborda explícitamente en el segundo capítulo del primer volumen de sus memorias el tema de las interferencias culturales en la lengua hablada por sus abuelos en la casa de su infancia en Aracataca:

La lengua doméstica era la que sus abuelos habían traído de España a través de Venezuela en el siglo anterior, revitalizada con localismos caribes, africanismos de esclavos y retazos de la lengua guajira, que iban filtrándose gota a gota en la nuestra. La abuela se servía de ella para despistarme sin saber que yo la entendía mejor por mis tratos directos con la servidumbre. Aún recuerdos muchos: atunkeshi, tengo sueño; jamusaitshi taya, tengo hambre; ipuwots, la mujer encinta; ariju$n a$, el forastero [...] (2002, p. 81-82).

Este comprobado contacto cultural nos permite hoy vislumbrar la existencia de relaciones de homología entre el personaje Melquíades y el chamán de la sociedad amerindia guajira, algunos de cuyos miembros participaron en la "educación" de García Márquez en su infancia. Esta nueva perspectiva nos permite salir del monotopismo crítico y borrar la frontera impermeable que antes separaba la institución Literatura de la heterogeneidad cultural de la sociedad en la que el escritor se formó como persona y nos permite leer en la intriga novelesca el aporte del pensamiento amerindio del mundo. En efecto, los comportamientos sobrenaturales de algunos personajes de Cien años de soledad, tales como la predicción, las aventuras de conocimiento del mundo a través la dimensión onírica y la significación de la muerte como nueva forma de vida (MORENO BLANCO, 2002a, 2002b) pueden ser comprendidas como experiencias humanas al interior del universo doble o 
de doble dimensión de la cultura chamánica guajira (PERRIN, 1976, 1992). Es ahí donde la teoría de la ficcionalización de la oralidad que hemos evocado muestra sus límites, pues si la escritura de García Márquez no comporta la tematización de la oralidad ni huellas lingüísticas que den testimonio de la influencia de una cultura amerindia, ella expresa el pensamiento y la gnoseología mítica guajira a través de esos personajes que, a imagen del chamán, se mueven entre lo natural y lo sobrenatural. La incorporación de la oralidad y de la tradición narrativa amerindia a la narrativa de García Márquez, al no corresponder al modelo teórico que pretendía cartografiarla, será tenida como inexistente y, en consecuencia, la crítica literaria seguirá más bien la tesis que consiste en insertar esta literatura en la estela de la novela Occidental. Tenemos aquí el ejemplo de situaciones en que la teoría puede contribuir a volver ilegible la alteridad.

\section{LOS CORTEJOS DEL DIABLO(1970) ET LA TEJEDORA DE CORONAS(1982)}

La tejedora de coronas es la novela que hizo célebre en Colombia al escritor Germán Espinosa (1938). Para abordar la recepción que el lectorado brindó a esta novela, nos parece oportuno citar dos pasajes de la nota escrita a su respecto en el periódico Le Monde, con ocasión de la aparición de su traducción al francés:

Composer le portrait d'un siècle tout entier - et quel siècle! - dans un roman totalisant (totalitaire?), d'un foisonnement prodigieux, vertigineux, en suivant la vie et les aventures d'une femme du XV TIIe siècle, une belle créole native de Carthagène-des-Indes [...].

Un roman immense sur fond de ce siècle des lumières français qui a, on le sait, fasciné les Latino-Américaines; un livre délirant, érudit, plein de science et de culture, de fornication et de violence [...] (ZAND, 1996).

Estas notas, hechas para el lectorado francés, resumen sorprendentemente la opinión que el público colombiano se hizo de esta novela en los años ochenta. En esto podemos reconocer un gusto común a los dos lados del Atlántico y que nos recuerda el trazado interpretativo hecho a la novela El siglo de las luces del cubano Alejo Carpentier. La novela de Espinosa entraría entonces en un canon en el cual la novela tematiza la inserción de la historia nacional dentro del proyecto de la Ilustración. Pero al comparar este éxito editorial con su primera novela, nos damos cuenta de grandes cambios en la escritura de Germán Espinosa. Los cortejos del diablo, publicada doce años antes, es una novela construida por una proliferación de voces desde la cual se eleva una imagen contrastada de la ciudad colonial Cartagena, en donde es posible percibir el choque de tres culturas: europea, africana, amerindia. Con La tejedora de coronas el escritor a adelgazado su estilo construyendo la imagen de la misma ciudad a partir de una enunciación y de una conciencia única. Aparte de la elección estilística, el novelista escogió también el representar en su segunda novela un mundo y una historicidad cuyos principales polos de tensión 
resident en Europa: de un lado el pensamiento de la Ilustración y del otro la tradición de la España católica e imperial. Así, podemos leer de parte de críticos colombianos interpretaciones del tenor siguiente:

Esta aproximación al pasado lejano contribute muy significativamente $[\ldots]$ a plantear la influencia de las ideas iluministas en América, la noción de la libertad y del progreso, la importancia de la ciencia y el saber, aspectos estos que han sido aprendidos y modificados sincréticamente por Genoveva en Europa al ingresar a las logias masónicas de mucho auge por entonces, para luego difundir en nuestro continente, en una gesta intelectual y existencial que le cuesta la sentencia de muerte dictada por la Santa Inquisición de Cartagena de Indias. Genoveva Alcocer simboliza, en este sentido, la búsqueda de la libertad en un siglo de oscurantismo, la afirmación de la ciencia sobre los dogmas religiosos (VALENCIA SOLANILLA, 1993, p. 482).

Ya no leemos en su escritura el decir popular que pertenece a todos y a nadie y que en Los cortejos del diablo nos daba identidades densas en las que todas las fuerzas y todos los discursos en conflicto en la sociedad colonial tomaban cuerpo. Para mostrar el contraste entre los dos mundos coloniales imaginados por Espinosa podemos evocar a la bruja, personaje común a las dos novelas y, sin embargo, tan diferente en su acción y en su fuerza. Mientras que en su primera novela la bruja Rosaura García se opone al poder de la Inquisición, al punto de dirigir a la muchedumbre contra ella, en la segunda la bruja de San Antero es un personaje discreto y pasivo que hace una predicción al personaje principal o sirve de testigo al monólogo de éste. Esta diferencia no es banal si tenemos en cuenta el hecho de que en el mundo colonial la brujería, siendo sobre todo una categoría del código inquisitorial, encarnaba una forma de resistencia y contestación activa contra la autoridad espiritual y política española. Los actores de esta práctica se nutrían probablemente de representaciones y tradiciones narrativas que venían de las culturas africanas y amerindias. Pero debemos constatar que la recepción deparada a $L a$ tejedora de coronas hizo olvidar el mundo complejo y mestizo de la primera novela y que el gusto del lectorado prefirió el mundo ordenado según el programa ideológico de la Ilustración en el cual "la ciencia" y "la razón" tienden a volver invisibles las discursividades otras, en el margen de la cultura letrada. Así, la novela que comportaba la ficcionalización de la oralidad anclada en las culturas subalternas es reducida a un plano secundario en tanto que la novela que inserta el pensamiento americano anticolonialista dentro del proyecto de la Ilustración es recepcionada por un público "bien educado" por las instituciones administradoras de la interpretación y que reconoce un periodo de la "historia nacional" dentro del marco de la historicidad de un pensamiento que se quiere "universal". En el ínterin, la narrativa otra, de la historicidad otra, sigue aguardando a los cartógrafos liberados de las ideas de la "universalidad". 
La recepción de las obras de los dos últimos escritores abordados muestra que las líneas imaginarias, que al cartografiar canonizan, construyen no solamente caminos para orientar al interior de la biblioteca sino también líneas que, como fronteras impermeables, sirven para conservar cierta idea de lo que se debe leer y de cómo se debe leer. Tal situación pone en evidencia el hecho de que no hay teoría pura sino que ésta puede, a veces, obedecer a prejuicios, estereotipos o a ideologías refractarias al reconocimiento de la heterogeneidad cultural.

Esta actitud, que vuelve invisibles los factores de oralidad, y, en consecuencia, las tradiciones narrativas subalternas, lleva a la teoría a servir a las ideologías. Ella podría ser debida a la longevidad de dos representaciones bien ancladas en la cultura colombiana.

La primera es la tendencia, que viene desde los estudios de la literatura colonial, que consiste en tener en cuenta solamente los rasgos literarios de los textos y documentos sin observar para nada su relevancia cultural. Según esta tradición, sólo entran en el canon los textos tenidos como literarios o cuyo género se le aproximan; por lo tanto, todo el conjunto de realidades expresivas que tienen que ver con la oralidad o la escritura no alfabética están excluidas (MIGNOLO, 1986). La segunda, más específica a la región caribe colombiana, es la representación según la cual el rasgo principal de esta cultura regional es la fuerte presencia del substrato africano y, por contraste, la presencia mínima del substrato cultural amerindio. En esta representación, que por lo demás es visible en los estudios sobre la musica "costeña", los amerindios se habrían marginalizado de los intercambios culturales o simplemente su herencia se habría perdido en el olvido.

Si representaciones de este tipo vienen a tomar la delantera en el trabajo de interpretación y los mapas de las instituciones que interpretan nos privan de la legibilidad de una parte del sentido del territorio-biblioteca, es importante subrayar que ellas obedecen a un imaginario geopolítico en el cual se establece una jerarquía entre una narrativa central, conforme a los criterios de "literalidad", y las narrativas de posición periférica, igual que entre una cultura "culta" y las culturas otras. Es en esa medida que podemos decir que las soluciones teóricas, desde las cuales trazamos las líneas de la cartografía canónica de nuestra literatura, jamás podrán escapar a la tensión que la presencia cada vez más importante de las tradiciones narrativas subalternas imprime a todas las expresiones de la Modernidad Heterogénea Latinoamericana. 


\section{REFERÊNCIAS}

CAPTAIN-HIDALGO, Yvonne. El espacio del tiempo en Changó el gran putas. Ensayos de Literatura Colombiana. Raymond L. Williams. (Ed.). Bogotá, Plaza \& Janés, 1984, p. 157-166. KERMODE, F. El control institucional de la interpretación. El canon literario, E. Sullá. (Ed.). Madrid, Arco/Libros, 1998.

MIGNOLO, Walter. La letra, el territorio (o la crisis de los estudios literarios coloniales). Dispositio, n. 28-29, The University of Michigan, p. 137-161, 1986.

MINTA, Sephen. García Márquez: Writer of Colombia. New York, Harper \& Row, 1987.

MORENO BLANCO, Juan. Transculturación narrativa amerindia en la obra literaria de Gabriel García Márquez. Estudios de Literatura Colombiana, n. 10, Medellín, Colombia, Universidad de Antioquia, p. 41-58, junio 2002a.

MORENO BLANCO, Juan. Emigración y transculturación wayúu en la Aracataca de Gabriel García Márquez. Diálogos Latinoamericanos, n. 5, Universidad de Aarhaus, Dinamarca, p. 24-39, 2002b.

MOLA, Lucila Inés. La función de la bistoria en «Cien años de soledad». Bogotá, Plaza \& Janés, 1979.

PACHECO, Carlos. La comarca oral. La ficcionalización de la oralidad cultural en la narrativa latinoamericana contemporánea. Caracas, Ediciones La Casa Bello, 1992.

PERRIN, Michel. Le chemins des Indiens morts. Payot, 1976.

PERRIN, Michel. Les praticiens du rêve. Un exemple de chamanisme. Paris, P. U. F., 1992.

POZUELO YVANCOS, José María; ARADRA SANCHEZ, Rosa María. Teoría del canon y literatura española. Madrid, Ediciones Cátedra, 2000.

RAMA, Angel. La ciudad letrada. Hanover, Ed. del Norte, 1984.

VALENCIA SOLANILLA, César. La novela colombiana contemporánea en la modernidad literaria. Manual de Literatura Colombiana, t. II. Santa Fe de Bogotá, Procultura/Planeta, 1993, p. 463-510.

ZAND, Nicole. Femme des Lumières. Le Monde, 19 janvier, 1996, p. IV. 
